\title{
Microscopía digital y herramientas colaborativas: la evolución de la docencia práctica en Anatomía Patológica
}

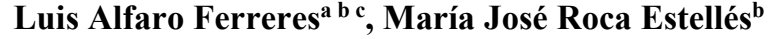 \\ aUniversidad CEU-Cardenal Herrera. Castellón, ${ }^{b}$ Hospital 9 de Octubre. Valencia y ${ }^{c}$ FISABIO \\ Oftalmología Médica. Valencia
}

\begin{abstract}
Learning practical skills of pathology at the university programs gets huge benefits from the application of digital methodology. It is based on the scanning of microscopic glass slides to obtain high resolution and high quality images that are studied on computer screens with specific visualization software. Students adapt very easily to the digital methodology that allows a closer interaction with the teachers and to incorporate a greater number of cases in each session, as well as facilitate the consultation of them in any location and at any time. The collaborative digital tools allow the simultaneous study of cases by students and teachers and a great capability in the orientation of the study even in remote work. The organization of a practical digital system has an affordable cost and can be implemented by pathology teachers themselves without a high knowledge in informatics.
\end{abstract}

Keywords: pathology, digital microscopy, whole slide images

\begin{abstract}
Resumen
La docencia práctica universitaria de anatomía patológica se beneficia enormemente de la aplicación de metodología digital. Se basa en el escaneo de las preparaciones microscópicas para obtener imágenes de alta resolución y gran calidad que se estudian en pantallas de ordenador con un software específico de visualización. Los estudiantes se adaptan con gran facilidad a la metodología digital que permite además una interacción más próxima con los profesores e incorporar un número mayor de casos en cada sesión, así como facilitar la consulta de los mismos en cualquier ubicación y en cualquier horario. Las herramientas digitales colaborativas permiten el estudio simultáneo de los casos por alumnos y profesores y una gran facilidad en la orientación del estudio incluso en trabajo remoto. La organización de un sistema práctico digital tiene un coste asequible y puede implementarse por los propios profesores sin un conocimiento informático elevado.
\end{abstract}

Palabras clave: Anatomía Patológica, microscopia digital, preparaciones microscópicas digitales. 


\section{Introducción}

La docencia práctica de anatomía patológica en los estudios de grado de medicina lleva desarrollándose de manera tradicional con preparaciones microscópicas, que los alumnos estudian en salas dotadas con microscopios ópticos convencionales. Esta metodología que se utiliza desde los inicios de la especialidad con la escuela de Cajal, está evolucionando desde la introducción de las tecnologías de información y la digitalización, que se extiende en todos los ámbitos de la docencia y de la sociedad en general (Weinstein, 2019).

La digitalización en microscopía se consigue con el empleo de escáneres que realizan un barrido completo de los portaobjetos de cristal que contienen las preparaciones histológicas. Son capaces de fotografiar a máximo aumento, habitualmente con objetivos de 40x para una resolución de 400x (aunque el empleo de objetivos con aceite de inmersión de 100x también está adaptado a los modernos escáneres) la totalizad de la muestra, que a través de un software de tipo fotográfico enlaza a modo de mosaico cada fotografía para generar una única imagen de enorme tamaño que reproduce todos los detalles de la preparación. La calidad de imagen que se consigue no solo es equiparable a la de un microscopio óptico, sino que llega a superarlos, gracias al empleo en los escáneres de objetivos de alta calidad y elevada apertura numérica. Los microscopios ópticos tienen un revolver que adapta una serie de objetivos de diferentes aumentos, que el observador va girando para explorar la preparación desde una imagen global a pequeño aumento, a una visión detallada a alto aumento de las áreas representativas que conducen al diagnóstico anatomopatológico. El equivalente en las imágenes digitalizadas se consigue en las pantallas de ordenador con programas de visualización que permiten la realización de zoom continuo y desplazamiento por toda la imagen. Esta tecnología es similar a la ya ampliamente difundida de información geográfica que emplean programas del tipo de Google Maps, Bing Maps o Waze entre otros (García, 2012).

La imágenes escaneadas de cada preparación microscópica tienen gran tamaño que puede llegar a los 200.000 x 100.000 pixeles. Los ficheros digitales incluso tras compresión alcanzan un tamaño de oscila entre los $100 \mathrm{Mb}$ y los $5 \mathrm{~GB}$. Hasta los más modernos ordenadores, servidores y redes de alta capacidad tienen dificultades en el manejo de estas imágenes. La soluciones que se emplean se basan en generar una estructura piramidal de imágenes de manera que para la visualización a bajo aumento, se descarga no la imagen completa a alta resolución y de enorme tamaño, sino otra re-escalada de pequeño tamaño y a la que se accede a gran velocidad (Fig. 1). Para el estudio de imágenes a gran aumento, no es necesario descargar la imagen completa de máxima resolución, sino que se descargan la áreas de interés que el observador selecciona como representativas de la lesión. Un patólogo experimentado obtiene la mayor parte de la información en los bajos aumentos y para el diagnóstico no suele necesitar recurrir a máxima resolución más que en una pequeña proporción de la imagen que puede ser inferior al 1\%. Aunque los estudiantes recurren con mayor frecuencia a grandes aumentos y lógicamente necesitan más tiempo para valorar una preparación microscópica o su equivalente digital escaneado, nunca se estudia la totalidad de la muestra a máximo aumento. 


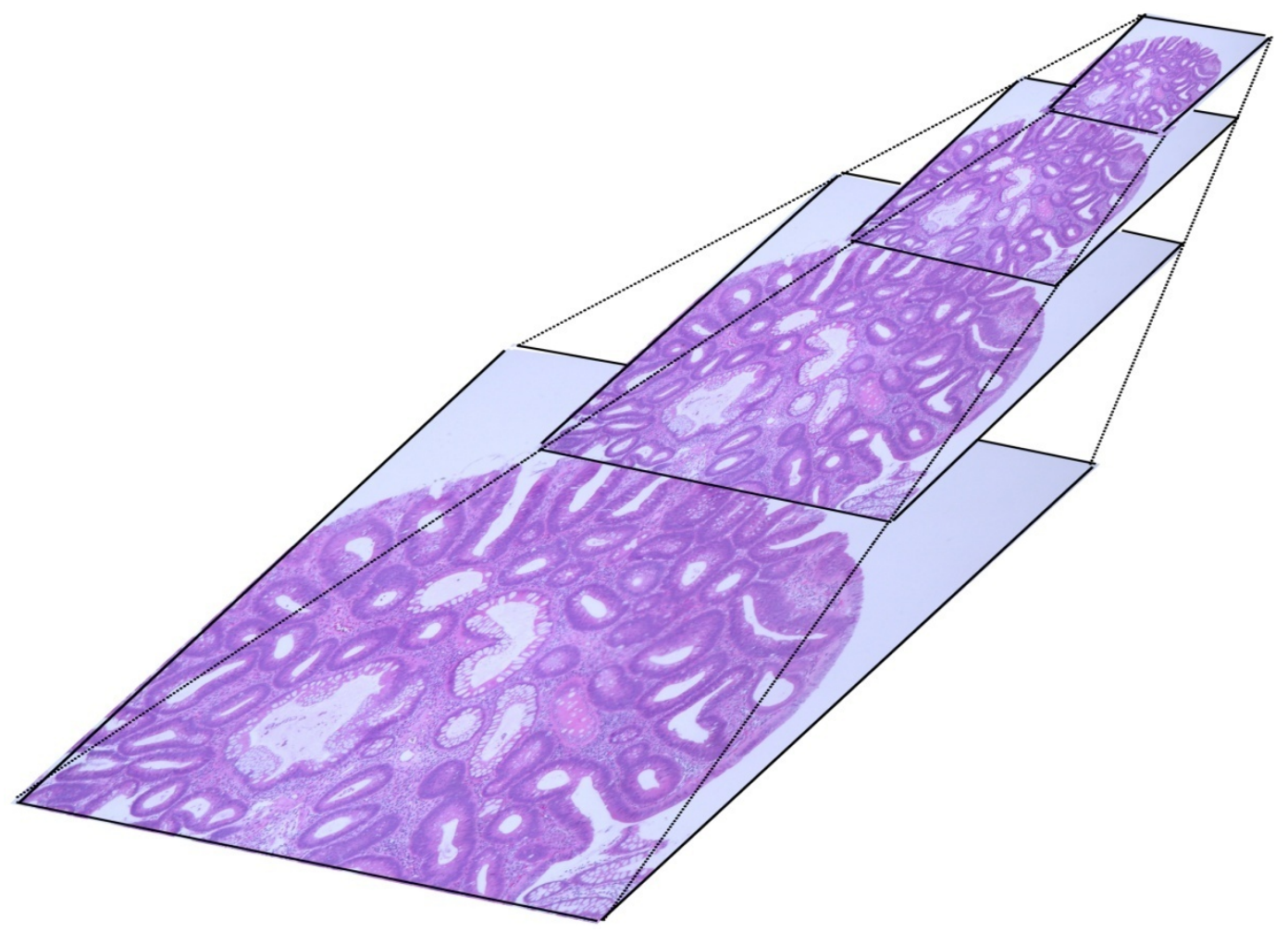

Fig. 1. Esquema de una imagen microscópica digital en formato piramidal para visualización secuencial en función del aumento deseado.

Los fabricantes de escáneres proporcionan con ellos un software para manejo y visualización de imágenes. Todos utilizan sistemas de compresión. Aunque algunos emplean algoritmos de compresión propios, comerciales y cerrados, es más habitual que se empleen como compresiones los sistemas más habituales utilizados en otros ámbitos como jpg2000 y jpg. El primero proporciona mayores tasas de compresión para calidades de imagen equivalentes, pero tiene un grado de compatibilidad menor entre diferentes visores. La compresión jpg aunque antigua y superada en cuanto a tasa de compresión, sigue empleándose en base a su elevada compatibilidad y por ser gratuita (Mea, 2017).

Los formatos de las imágenes que se emplean son muy variados y habitualmente diferentes entre cada fabricante. Sin embargo, muchos de ellos permitan la exportación a formatos habituales como .tiff ó .jp2. Por otro lado los visores suelen ser capaces de abrir formatos de otras empresas si éstas mantienen compresión convencional jpg.

Para la visualización de las imágenes digitales es necesario disponer de un servidor específico que permita la funcionalidad de no descargar la imagen completa, como haría un servidor web convencional ante la petición de acceso a una imagen, sino únicamente a las áreas de interés (Hartman 2017). Estos servidores deben ser además capaces de gestionar el acceso simultáneo de múltiples estudiantes a las imágenes ya que el modelo de sesiones prácticas, aunque en grupos reducidos, implica el manejo simultáneo de las mismas imágenes por todo grupo de prácticas. 
El precio de los escáneres y del software de los servidores suele ser elevado. Los visores suelen ser gratuitos proporcionados por los fabricantes de escáneres. En el ámbito universitario docente no es necesario el empleo de escáneres de alta capacidad y velocidad como en los hospitales, donde un elevado número de casos debe ser digitalizado diariamente para el diagnóstico por parte de los patólogos. En la actualidad un escáner de preparaciones microscópicas adaptable a las necesidades docentes de una universidad tiene un precio que oscila entre 30.000 y 80.000 euros. El software servidor de preparaciones digitales microscópicas suele ser incompatible entre los distintos fabricantes de equipos y su precio se encarece proporcionando funciones complejas como gestión de usuarios y contraseñas o funcionalidades propias del diagnóstico hospitalario

\section{Objetivos}

La docencia práctica en los estudios de anatomía patológica para el grado de medicina busca trasmitir a los alumnos la enormes capacidades del diagnóstico histopatológico. Antes que aprender a diagnosticar deben entender las limitaciones y las contraidicaciones para prescribir estudios biópsicos y citológicos. El aprendizaje de la metodología diagnóstica y de los criterios morfológicos, les capacitará tomar decisiones frente a cada futuro paciente, indicando analíticas de laboratorio, pruebas de imagen radiológicas o tomas biópsicas.

La implantación de un sistema completamente digital de docencia práctica en anatomía patológica pretende sustituir las salas de microscopios por el empleo de pantallas de ordenador o cualquier dispositivo de visualización de imágenes gráficas.

El tiempo de adaptación de los estudiantes al manejo de microscopios ópticos es habitualmente prolongado. Los alumnos encuentran dificultades para familiarizarse en su uso y para seguir las explicaciones de los profesores e identificar las lesiones y discernir los criterios diferenciales de cada una de ellas.

El manejo de dispositivos digitales no requiere ningún tiempo de adaptación. Los alumnos se encuentran cómodos en entornos gráficos digitales y aprenden con rapidez el manejo de los dispositivos de visualización.

El paso de preparaciones microscópica sobre portaobjetos a imágenes digitales implica que todos los estudiantes ven exactamente la misma imagen y no secciones consecutivas cortadas con micrótomo que suponen cierta variación y en ocasiones pérdida de algunos de los detalles de interés de los casos.

En las prácticas con microscopio el profesor suele tener que desplazarse para atender las dudas de cada alumno en su propio microscopio. Los sistemas digitales permiten una visualización simultánea de las mismas áreas orientadas por el profesor.

Las preparaciones en cristal suelen romperse y son difíciles de reponer con las mismas características. Las imágenes digitales pueden copiarse indefinidamente sin riesgo de pérdida (Poblet, 2013). 
Las limitaciones de los sistemas digitales que hemos intentado resolver son:

La disponibilidad de acceso a las imágenes graficas desde cualquier ubicación y dispositivo y no solo desde las aulas de prácticas de la universidad. Para ello es necesario adaptar la visualización a diferentes sistemas operativos y dispositivos (PC, tabletas, teléfonos móviles).

El empleo de formatos de imágenes que resulten compatibles con visualizadores universales.

El empleo de servidores que permitan el acceso en cualquier franja horaria y acepten en todo momento la conexión simultánea de diferentes observadores.

La exportación de imágenes procedentes de escáneres de diferentes fabricantes para trabajar con casos poco frecuentes, obtenidos habitualmente de diferentes fuentes hospitalarias (Bueno, 2016).

El empleo de herramientas colaborativas para el acceso universal y simultáneo de alumnos y profesores para tutorías y resolución de dudas y sesiones no programadas, al margen de los turnos de prácticas establecidos.

\section{Desarrollo de la innovación}

Nuestro equipo de digitalización en la Universidad consta de un escáner Leica SCN400 que genera imágenes en formato .scn con compresión jpg. El sistema de visualización es un software comercial de Leica: SlideHub diseñado para un entorno de PC con Windows y con Flash. Esta configuración impide su uso en dispositivos móviles y se ve limitada por la creciente obsolescencia de aplicaciones basadas en Flash.

Las fuentes de casos que utilizamos en docencia provienen de los hospitales donde los autores desarrollan su actividad asistencial. En ellos se dispone de dos escáneres de diferentes fabricantes. Un iCoreo de Roche que genera preparaciones en formato propietario .bif aunque permite obtener imágenes en formato mas habitual tiff. El segundo escáner e un MiraxMidi de 3D-Histech que genera imágenes en formato.mrxs aunque con compresión jpg.

Para poder manejar todas las imágenes de estas procedencias e incluso intercambiar con otras universidades hemos optado por utilizar un formato que permita una compatibilidad mayor. Para ellos inicialmente convertimos todas las imágenes de interés docente a un formato tiff con compresión LZW. Esta compresión es poco eficiente y genera ficheros que suelen superar los $10 \mathrm{~GB}$ e incluso alcanzan los 20-30 GB. Estos volúmenes no tienen aplicación práctica pero es un formato altamente compatible en cualquier visualizador y permite una segunda compresión sin ningún problema de compatibilidad.

La obtención de la imágenes tiff con compresión LZW la realizamos con un software gratuito ObjectiView que además es portable, por lo que puede utilizarse sin requerir instalación ni permisos de administrador (Fig. 2). 


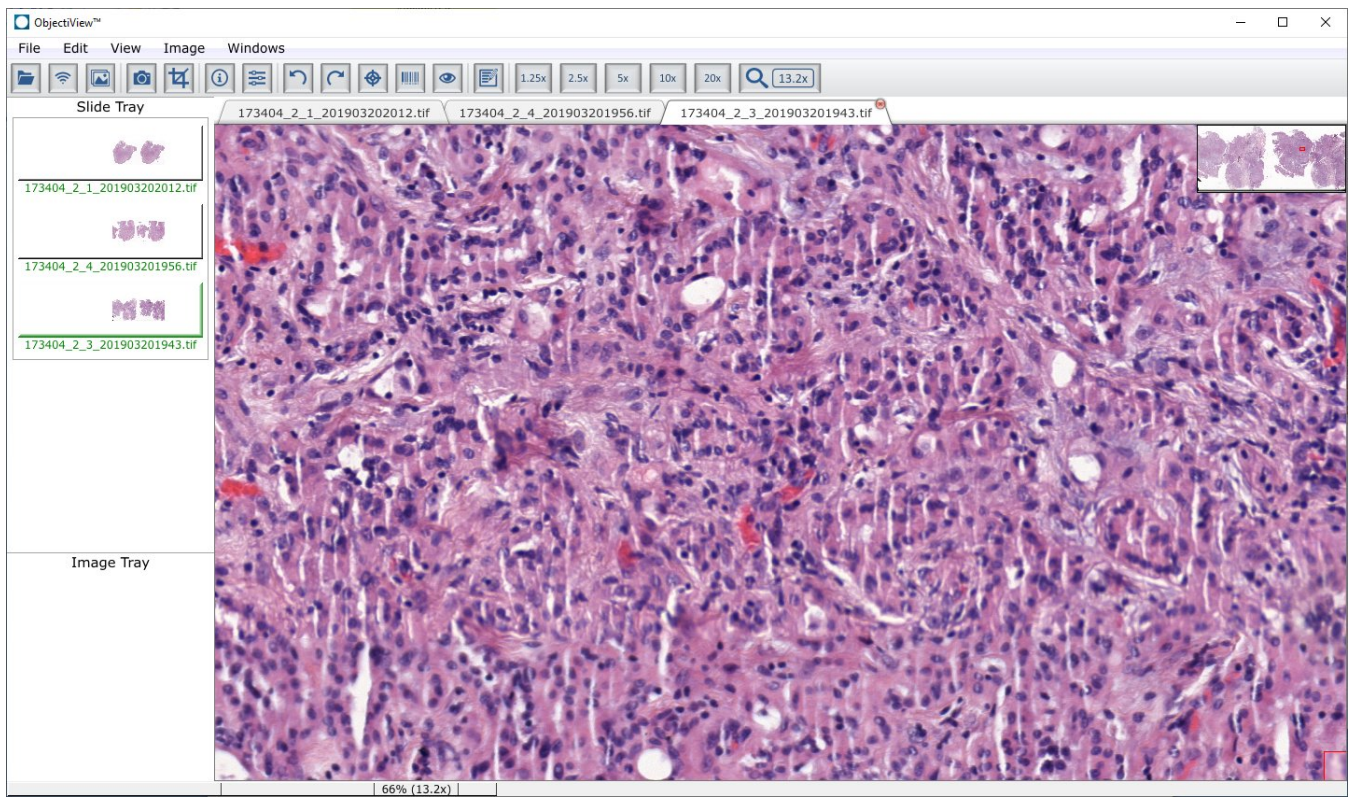

Fig. 2. Visor portable ObjetiviView de preparaciones microscópicas digitales con capacidad de lectura multiformato y de exportación a otros formatos

A partir de estas imágenes generamos un entorno de trabajo con una solución gratuita (y con un pequeño coste en la versión avanzada) de la compañía Zoomify inc. Esta solución genera ficheros de tipo .zif con compresión jpg. El visor es en la práctica cualquier navegador web y el servidor es multiplataforma basado en HTML5 (Fig. 3), apto para ser situado en cualquier servidor web sin instalar ejecutables y con el manejo únicamente de un pequeño fichero de control .js, una página web en formato html fácilmente configurable por los profesores (patólogos sin formación en programación ni elevados conocimientos informáticos) y la imagen escaneada convertida a formato .zif (Alfaro, 2008). 


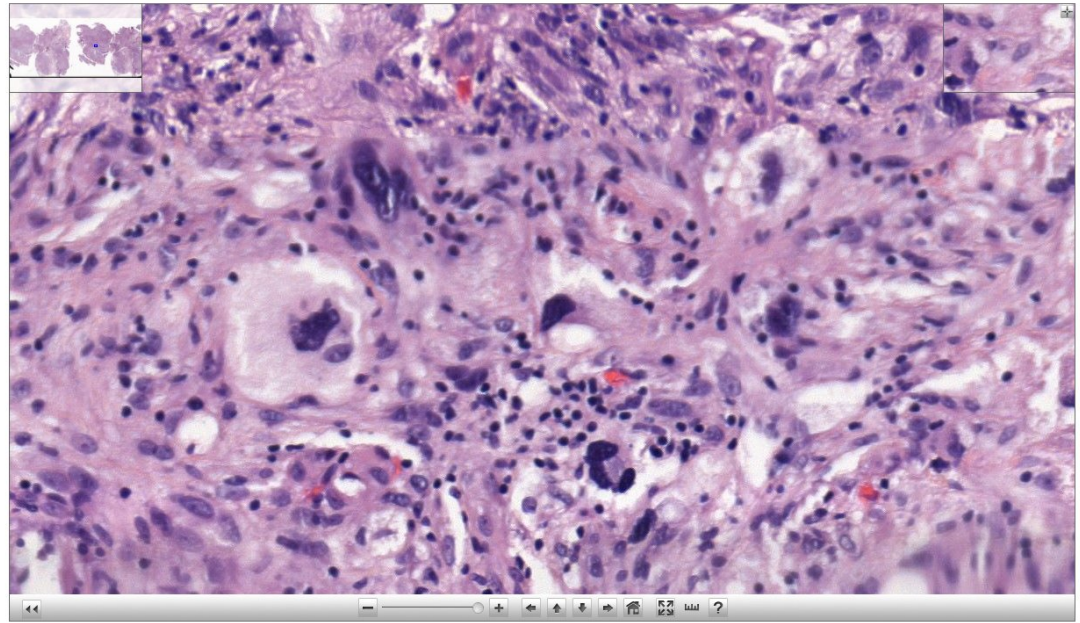

Fig. 3. Visor web multiplataforma e preparaciones digitales sobre un navegador convencional con diseño HTML5

Esta metodología transforma nuestro sistema de patología microscópica digital en accesible para los estudiantes desde cualquier ubicación horario y plataforma.

Para poder ejercer una supervisión eficiente y seguimiento en tiempo real del manejo de los alumnos de los visores de preparaciones microscópicas incorporamos herramientas colaborativas, en nuestro caso "slack". Esta plataforma ideada para un trabajo genérico en común con documentos, graficas, tablas etc. es apropiada para compartir en tiempo real nuestros visores de preparaciones digitales y además puede hacerse manera bidireccional, es decir, el alumno sigue el proceso de exploración de la preparación digital guiado por el profesor o bien el profesor supervisa en tiempo real la aproximación del alumno al diagnóstico con la visualización de las imágenes y orienta hacia áreas concretas de interés.

\section{Resultados}

La implantación de las prácticas de anatomía patológica se realizó desde el inicio del grado de medicina en nuestra universidad en 2012, en el tercer curso donde se imparte la asignatura. Ningún curso ha utilizado microscopios y la evolución ha consistido en perfeccionar el sistema digital implantando la metodología descrita. Aunque los alumnos no han tenido ocasión de comparar ambas metodologías la clásica con microscopio, frente a la completamente digital, la experiencia de los profesores ha sido enormemente positiva. El recuerdo propio del tiempo de adaptación a los microscopios contrasta con la inmediatez en la adaptación a las pantallas con los casos digitales. El alumno tiene que centrarse exclusivamente en el reconocimiento e identificación de las lesiones y no se ve retrasado por tediosos tiempos de adaptación metodológica. La facilidad de los alumnos en el manejo 
de los sistemas digitales contrasta con la torpeza que experimenta cualquier usuario que se sienta por primera vez frente a un microscopio.

El número de casos presentados a los alumnos se ha ido incrementando con el perfeccionamiento de nuestro sistema digital contribuyendo a una mejor perspectiva global de la materia y un mejor dominio de las diferentes patologías.

Curiosamente ningún tipo de reticencias han surgido por parte de los alumnos y solo algún profesor incorporado después de la implantación digital, añoraba el sistema tradicional que había empleado de manera exclusiva a lo largo de muchos años.

Incluso para estos profesores la vuelta atrás a la sala de microscopios resulta inviable pues requiere un enorme trabajo de selección de casos, realización de cortes múltiples para grupos de prácticas, mantenimiento de los microscopio, enseñanza a los alumno del manejo de los mismos, sustitución de casos dañados o rotos y limitación del tiempo de visualización de los casos al horario designado para cada grupo de prácticas.

El incremento de las habilidades diagnósticas de los alumnos ha mejorado al ir incorporando un mayor número de casos y una exposición mayor a los visores de preparaciones diagnósticas. El objetivo del curso, en el grado de medicina, no es formar expertos en diagnostico histológico (ello correspondería a la especialización y la residencia en anatomía patológica) sino proporcionar a los alumnos, futuros médicos generales o especialistas, nociones de lo que pueden esperar en un ámbito hospitalario de las muestras biópsicas y citológicas. Estas habilidades diagnósticas se evalúan exclusivamente en las prácticas de la asignatura, de manera que no restan de la parte teórica, pero si incrementan la valoración en la evaluación global.

\section{Conclusiones}

La instauración de modelos de prácticas digitales en Anatomía Patológica se ha venido imponiendo en numerosas universidades en los últimos años. Las ventajas resultan tan indudables y el apoyo y preferencia de los alumnos es compartido allí donde se establece, lo que ha hecho que la docencia haya conseguido una tasa de implantación muy superior a los hospitales puramente asistenciales, donde el manejo de microscopio óptico sigue siendo aun mayoritario.

Para los alumnos el acceso universal a un gran número de casos de gran valor docente ha permitido definir mejor lo que es la especialidad. En nuestro medio la carga docente dedicada a la fisiopatología o anatomía patológica general se ha venido sustituyendo por la denominada anatomía patológica especial en la que se describe el diagnóstico de los diferentes procesos lesionales que se desarrollan en cada órgano o aparato. Ello acerca nuestra especialidad a los objetivos globales de la universidad de proporcionar a nuestros alumnos un formación directamente orientada al desarrollo práctico de la especialidad, no solo para aquellos que opten por una especialización en el futuro en anatomía patológica sino para la inmensa mayoría, quienes desde diferentes especialidades médicas clínicas o quirúrgicas requerirán el concurso de los patólogos para el diagnóstico de certeza de sus 
pacientes y es ineludible conocer las bases de la especialidad para poder prescribir una prueba biópsica o citológica y para interpretar los resultados de esas pruebas y aplicarlos con eficiencia en los pacientes.

\section{Referencias}

ALFARO FERRERES, L. y ROCA ESTELLÉS, M.J. (2008). "Portable Telepathology: Methods and Tools". Diagnostic Pathology, Vol. 3 (Suppl. 1), p. 19-21.

BUENO G, FERNÁNDEZ-CARROBLES MM, DENIZ O, GARCÍA-ROJO M. (2016). "New "Trends of Emerging Technologies in Digital Pathology". Pathobiology;83(2-3):61-9.

GARCÍA ROJO M (2012). "State of the art and trends for digital pathology". Stud Health Technol Inform.179:15-28.

HARTMAN DJ1, PANTANOWITZ L2, MCHUGH JS3, PICCOLI AL3, OLEARY MJ3, LAURO GR3. (2017)

"Enterprise Implementation of Digital Pathology: Feasibility, Challenges, and Opportunities". J Digit Imaging. 30(5):555-560. doi: 10.1007/s10278-017-9946-9.

MEA VD, CARBONE A, DI LORETO C, BUENO G, DE PAOLI P, GARCÍA-ROJO M, DE MENA D, GLOGHINI A, ILYAS M, LAURINAVICIUS A, RASMUSSON A, MILIONE M, DOLCETTI R, PAGANI M, STOPPINI A, SULFARO S, BARTOLO M, MAZZON E, SOYER HP, PANTANOWITZ L (2017). "Teaching Digital Pathology: The International School of Digital Pathology and Proposed Syllabus". J Pathol Inform. 25;8:27

POBLET MARTÍNEZ, E., MORO RODRÍGUEZ, E., ALFARO FERRERES, L. (2013). "Patología digital y docencia” en: Libro Blanco de la Anatomía Patológica en España. C SEAP, págs. 105-109.

WEINSTEIN RS, HOLCOMB MJ, KRUPINSKI EA. (2019). "Invention and Early History of Telepathology (1985-2000)". J Pathol Inform;10:1 